\title{
REACTIVE SPUTTERING OF NiCr RESISTORS WITH CLOSELY ADJUSTABLE TEMPERATURE COEFFICIENT OF RESISTANCE
}

\author{
JÜRGEN GRIESSING \\ Siemens AG, München BRD, West Germany
}

(Received May 1, 1977)

\begin{abstract}
A process is described to obtain $\mathrm{NiCr}$ resistors with adjustable temperature coefficient of resistance (TCR) by reactive sputtering in an Ar-atmosphere with a small amount of oxygen in the range of $2 \%$ to $6 \%$. As deposited the films show a TCR $<-200 \mathrm{ppm} / \mathrm{K}$. By heat treatment in air at a temperature of $350^{\circ} \mathrm{C}$ the TCR can be raised to values above $-20 \mathrm{ppm} / \mathrm{K}$. The time of heat treatment necessary to obtain a given TCR depends on the oxygen/argon ratio during sputtering. The long term stability is not affected by the choice of this ratio in a wide range.

Resistor networks with a solderable conductor pattern of TiPdAu have a TCR of $0 \pm 7 \mathrm{ppm} / \mathrm{K}$ and a long term resistance drift $\leqslant 2 \%$ in the first 1,000 hours at $125^{\circ} \mathrm{C}$.
\end{abstract}

\section{INTRODUCTION}

There is a growing interest in temperature-independent electronic devices. Whereas a broad spectrum of low-cost chip capacitors meeting this requirement are already available as passive devices, temperatureindependent resistors as discrete elements or incorporated in hybrid ICs are more expensive and rather rare. The objective of our investigations was therefore to devise a variant technology which would open the way to controlling the temperature coefficient of resistance during resistor fabrication without the need for any major modification of the already well-established and mature process used for the fabrication of $\mathrm{NiCr}$ resistor networks. The solution to this control problem was found to be reactive sputtering in an atmosphere of $\mathrm{Ar}$ and $\mathrm{O}_{2}$.

\section{EXPERIMENTAL}

Figure 1 shows the triode system employed for reactive sputtering. In this system a sustained plasma discharge between a hot tungsten cathode and an anode is constrained by an externally applied axial magnetic field into the form of a cylindrical column. The cathode is accommodated in a water-cooled elbow section. The anode voltage is $45 \mathrm{~V}$ to $50 \mathrm{~V}$, the anode current $4.5 \mathrm{~A}$. The water-cooled target $(\mathrm{NiCr}$ $50 / 50$ at $\%$ ) adjoins the plasma column. The substrates to be coated are attached to a planetary carousel capable of accommodating up to six 4 in. by $4 \mathrm{in}$. substrates at a time. While the target is presputtered for the removal of contamination the substrates can be shielded by two semi-cylindrical shutters. To allow sputtering the movable inner shutter is pivoted into the fixed outer one. The final pressure of the sputtering system is $3 \times 10^{-7}$ millibar. The charged chamber is pumped to a pressure of $8 \times 10^{-7}$ millibar. Following the closure of a damper, the working gas in the form of an $\mathrm{Ar}-\mathrm{O}_{2}$ mixture (Ar: $99.998 \%, \mathrm{O}_{2}$ : 99.5\%) is fed from a supply vessel of $4 \times 10^{-3}$ millibar through a control valve into the chamber. The substrates are then treated by a plasma discharge sustained for 10 minutes with the shutter open, following which the target is pre-sputtered for 10 minutes with the shutter closed. The shutter is now reopened for sputtering proper. When a certain target charge has been reached the target voltage is removed and the gas inlet valve shut. The TiPdAu (50nm/ $400 \mathrm{~nm} / 600 \mathrm{~nm}$ ) film is then evaporation deposited in a second vacuum system and the pattern generated by conventional photolithography. After annealing at $350^{\circ} \mathrm{C}$ the resistors are trimmed with a laser beam.

\section{RESULTS}

Films with a sheet resistance of $100 \Omega$ each were realized. The working pressure and the Ar partial pressure were in all cases $4 \times 10^{-3}$ millibar; the $\mathrm{O}_{2}$ partial pressure was initially set between 0 and 


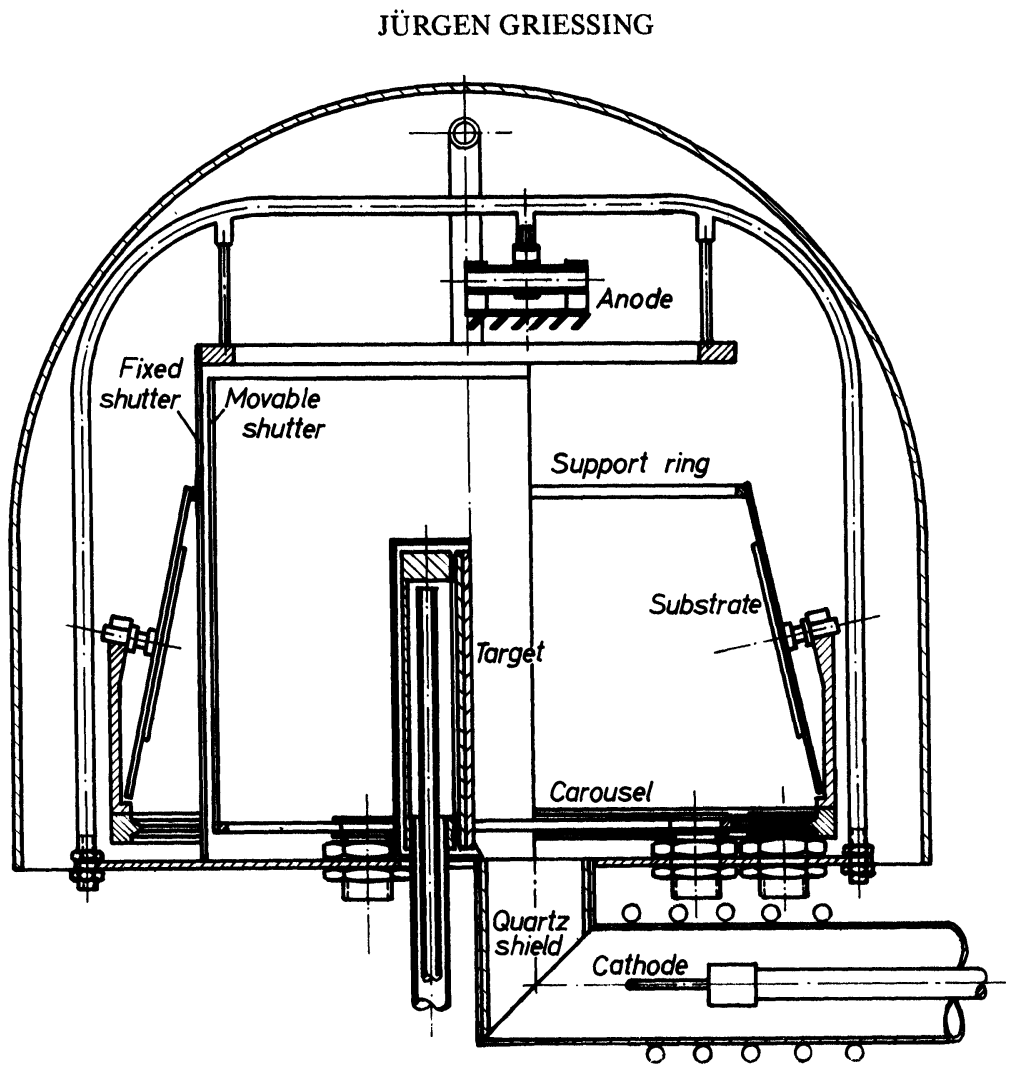

FIGURE 1 Sputtering system.

$1 \times 10^{-4}$ millibar. At the start of the sputtering process the oxygen is gettered so strongly that the $\mathrm{O}_{2}$ partial pressure decreases. In all future references the oxygen partial pressure will apply to the pressure before the start of the sputtering cycle. The films were annealed at $350^{\circ} \mathrm{C}$ in a circulating-air oven and their temperature coefficient of resistance monitored. Both the linearity and the absolute temperature coefficient were investigated. Figure 2 shows, as examples, the temperature dependence $\Delta R / R_{0}$ of films sputtered with $\mathrm{O}_{2}$ partial pressures of $5 \times 10^{-5}$ millibar and $1 \times 10^{-4}$ millibar followed by annealing. Curves varying in slope as a function of the annealing time were recorded. The slope of the curves represents a good approximation of the value of the temperature coefficient of resistance $(T C R)$ :

$$
\begin{aligned}
\text { temperature coefficient } \alpha & =1 / R \times(d R / d T) \\
\text { slope } & \alpha^{+}=d / d T \times\left(\Delta R / R_{0}\right) \\
\text { difference } & \alpha^{+}-\alpha=1 / R \times d R / d T \times\left(R / R_{0}-1\right) \\
& =\alpha \times R / R_{0}
\end{aligned}
$$

It is seen from Figure 2 that, over the temperature interval of interest, $\Delta R / R_{0}<2 \%$, which means that the error is far smaller than the measuring accuracy.
Figure 2 further shows

1) All the recorded curves to be almost linear and the temperature coefficient to be consequently almost constant.

2) The initially steep negative slope to rise monotonically with increasing annealing time and to tend asymptotically towards a limiting value.

3) This limiting value to be larger for $\mathrm{Po}_{2}=$ $5 \times 10^{-5}$ millibar than for $\mathrm{Po}_{2}=1 \times 10^{-4}$ millibar and consequently to decrease with rising $\mathrm{O}_{2}$ partial pressure.

The linearity justifies the definition of a single averaged temperature coefficient $\alpha$ (measured between $-40^{\circ} \mathrm{C}$ and $+100^{\circ} \mathrm{C}$ ). Figure 3 shows for this value the dependence of the temperature coefficient on the annealing time. The films investigated were sputtered with $\mathrm{O}_{2}$ partial pressures of 0.52 to $1 \times 10^{-4}$ millibar except for one which was sputtered without $\mathrm{O}_{2}$. The temperature coefficient is seen to increase steadily with the annealing time and the curves gradually level off. The $\alpha=0$ condition is satisfied for the following annealing times: 


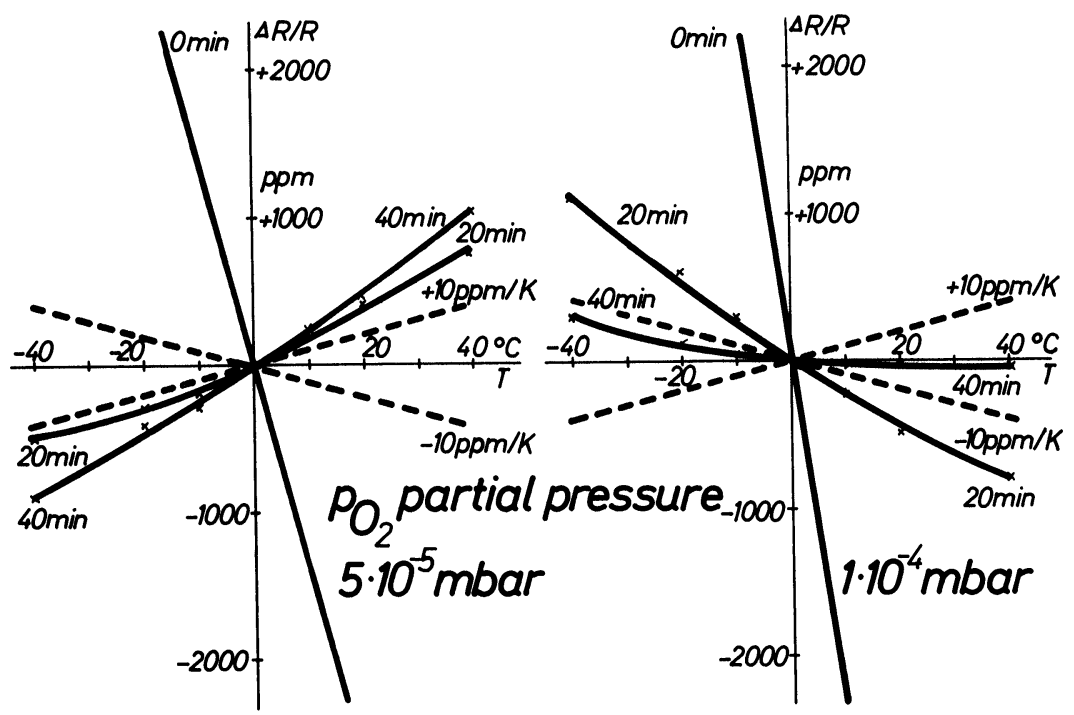

FIGURE 2 Change of resistivity vs. temperature.

$\mathrm{O}_{2}$ partial pressure in $10^{-5}$ millibar
5.2
6.5
7.8
9.1
10.4
20

Annealing time at $350^{\circ} \mathrm{C}$ in minutes

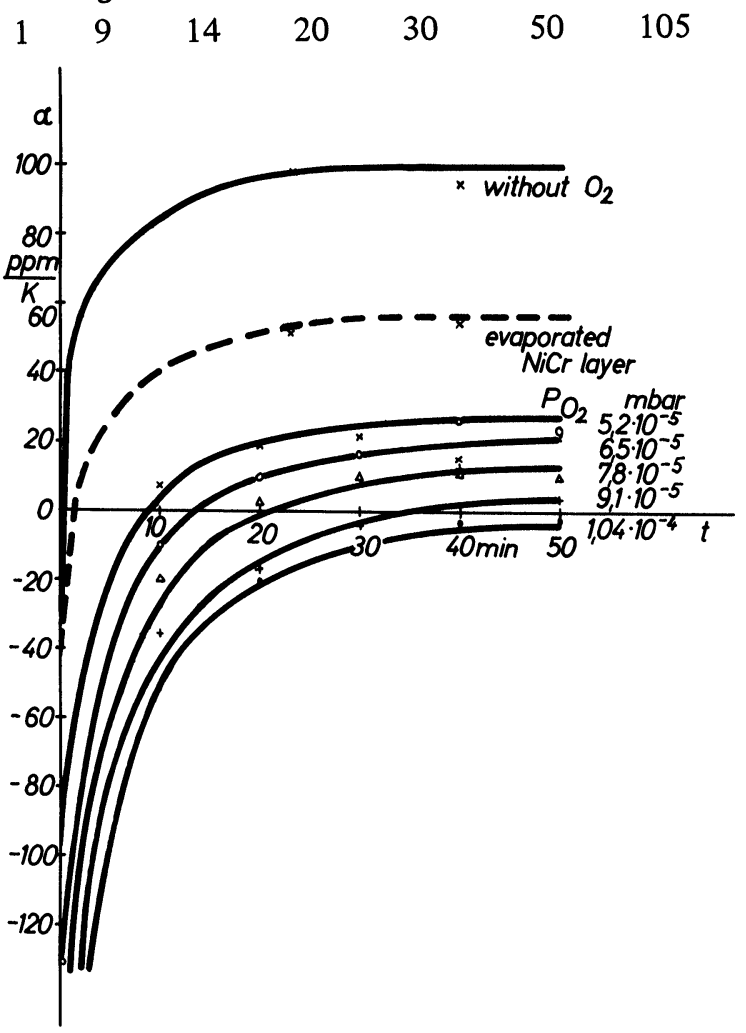

FIGURE 3 TCR vs. time of heat treatment.
Figure 4 shows the long-term behaviour of a total of 306 resistors drawn from 6 different sputtering charges and gives the $3 \sigma$ limits. The resistors had been stored at a temperature of $125^{\circ} \mathrm{C}$. The $3 \sigma$ limits refer to an $\mathrm{Ar} / 5 \% \mathrm{O}_{2}$ gas mixture with a corresponding $\mathrm{O}_{2}$ partial pressure of $2 \times 10^{-4}$ millibar. The films were annealed for 105 minutes in order to realize a temperature coefficient $\alpha=0$. The long-term behaviour of films sputtered with various $\mathrm{O}_{2}$ partial pressures and annealed as described to realize $\alpha=0$ is also shown. Surprisingly, all are found to lie within the error limits given for the $2 \times 10^{-4} \mathrm{mbar}$ film. Although process conditions were accordingly very different, all the films have the same sheet resistance, TCR and long-term resistance drift.

Figure 5 shows the long-term behaviour of the TCR of the 306 resistors and likewise their $3 \sigma$ limits. The temperature coefficient is seen to decrease slightly and its tolerance limits tend to diverge. The fabrication accuracy was $\pm 7 \mathrm{ppm} /{ }^{\circ} \mathrm{C}$. It has already been noted that the $\mathrm{O}_{2}$ partial pressure decreases during sputtering to a fraction of its original value due to the gettering effect of the deposited film. Figure 6 shows the smallness of this fraction. The parameter is the peak elevation ratio $I_{O_{2}} / I_{A r}$ measured with a quadrupole mass spectrometer during a sputtering cycle. The $\mathrm{O}_{2}$ partial pressure afterwards decreases due to the sputtering process to about $2 \%$ of its original value. It can be shown with the aid of the kinetic theory of gases that, for the incorporation of oxygen atoms in the $\mathrm{NiCr}$ film with the composition ratio $1: 1$ and a chamber temperature of $100^{\circ} \mathrm{C}$, 


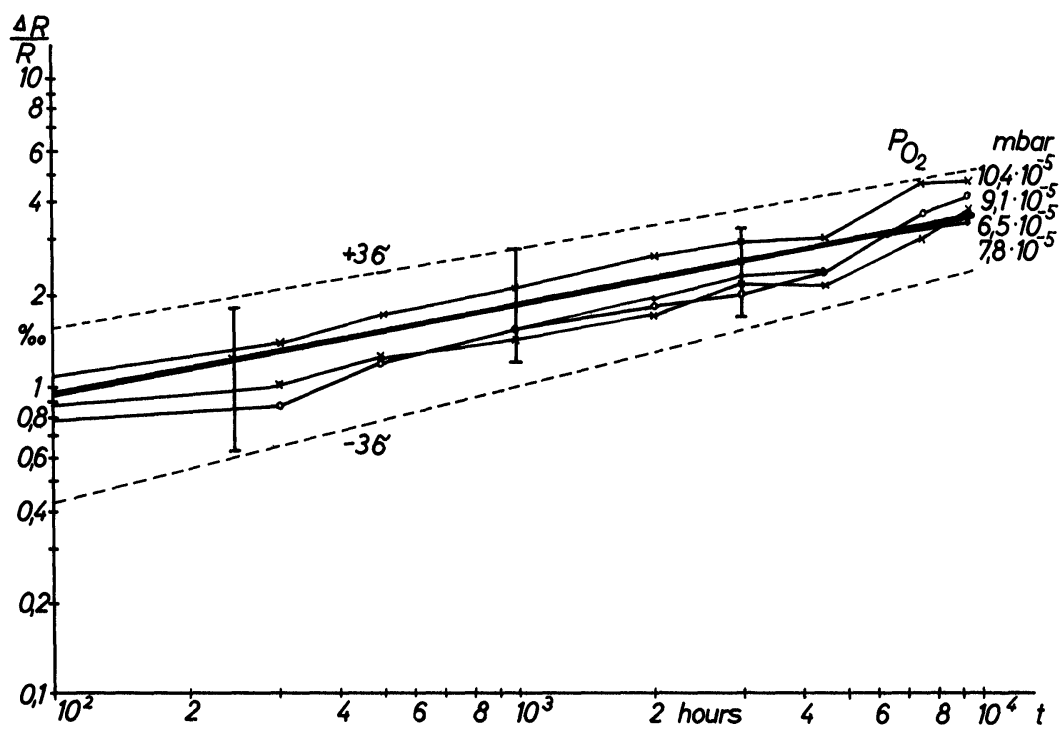

FIGURE 4 Long term stability of resistivity.

$$
b=5.55 \times 10^{4} \mathrm{Po}_{2} / r,
$$

where $b$ denotes the ratio of the number of gas atoms to the number of metal atoms in the film, $\mathrm{PO}_{2}$ is the partial pressure in millibar and $r$ is the sputtering rate in $\mathrm{nms}^{-1}$ for the pure $\mathrm{NiCr}$ film. It is seen from Figure 6 that during the sputtering process the $\mathrm{O}_{2}$ partial pressure must be about $4 \times 10^{-7}$ millibar. For $r=0.033 \mathrm{nms}^{-1}$ this would correspond to a ratio of the number of gas atoms to the number of metal atoms $b=2: 3$. Lassak and Hieber ${ }^{1}$ have observed in annealed $\mathrm{NiCr}$ films diffraction lines which can be associated with the oxide $\mathrm{NiCr}_{2} \mathrm{O}_{4}$. Hardy and Murti ${ }^{2}$ have found in annealed $\mathrm{O}_{2}$-doped $\mathrm{NiCr}$ films an expanded Ni lattice, from which they inferred the precipitation of an amorphous $\mathrm{Cr}_{2} \mathrm{O}_{3}$ phase. Our films also proved to be $\mathrm{x}$-ray amorphous with a grain size approx. $3 \mathrm{~nm}$ and it is conceivable from the estimated gas to metal ratio that the negative temperature coefficient may have been brought about by the mixture of conducting metallic phases with insulating or semiconducting oxide phases, whereby the oxide phase encompasses the metal phase in the manner of a net. It is further conceivable that the annealing process may cause the grain size of the metallic phase to increase at the cost of the oxide phase, as a result of which the TCR increases. The experimental results reported here are of course not sufficient by themselves to be offered as evidence of the existence of two phases under certain stoichiometric conditions. To settle this problem a far more sophisticated model would be needed.

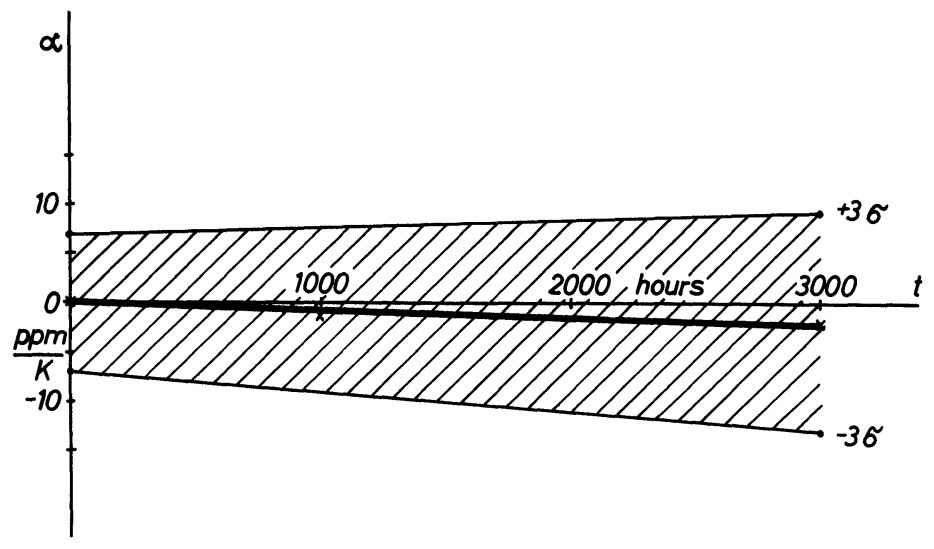

FIGURE 5 Long term stability of TCR. 


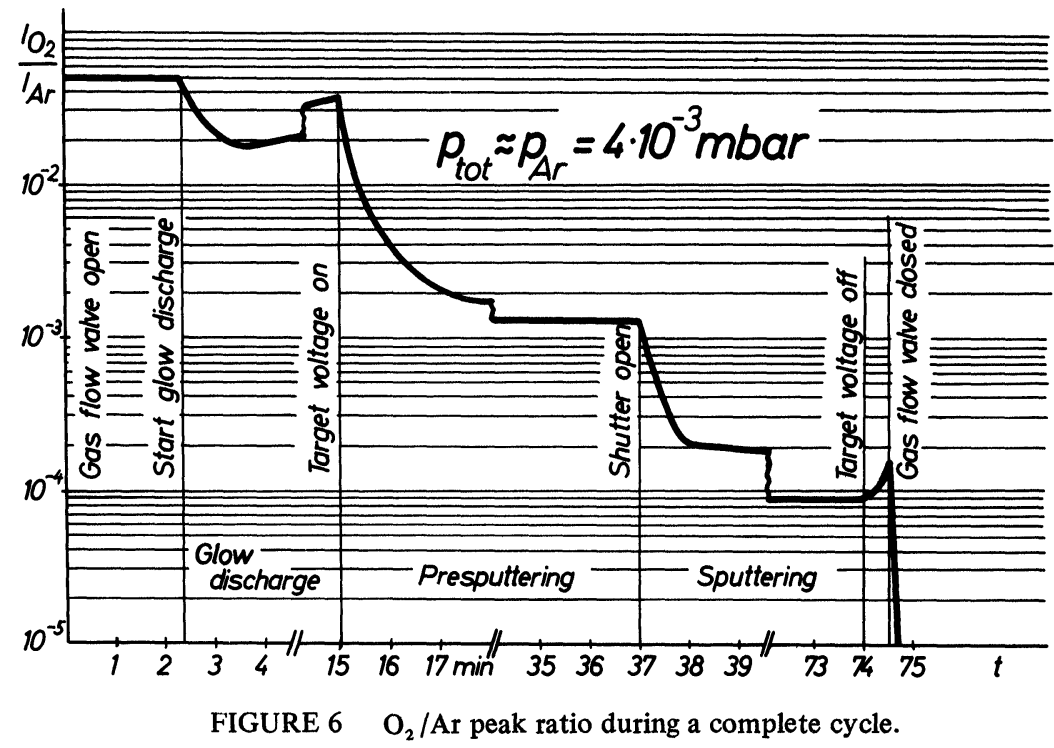

\section{CONCLUSIONS}

Thin-film metal resistors usually have excellent longterm stability. The following example will show however that this advantage cannot be fully exploited because in many cases their TCR cannot be neglected. A resistor with $\alpha=60 \mathrm{ppm} / \mathrm{K}$ that is exposed to a rise in operating temperature from $20^{\circ} \mathrm{C}$ to $70^{\circ} \mathrm{C}$ will increase by $0.3 \%$, which is much more than its total resistance drift of $0.2 \%$ after storage at $70^{\circ} \mathrm{C}$ for 15 years. ${ }^{3}$ For this reason we also use resistor networks of the type described as standards as well as in the analog section of the pattern generator of electron beam deflection systems (electron beam exposure unit), where owing to the rigorous resolution specifications of the analog deflection signals the beam position must not be influenced by temperature fluctuations. An oscillator implemented as a hybrid IC with NPO chip capacitors operates over a temperature range of 0 to $100^{\circ} \mathrm{C}$ with a frequency drift of $800 \mathrm{ppm}$.

\section{REFERENCES}

1. Lassak and Hieber, Thin Solid Films, 17, (1973), pp. 105-111.

2. Hardy and Murti, Thin Solid Films, 20, (1974), pp. 345362.

3. Kadereit and Thurman, Internal Report, Siemens AG. 

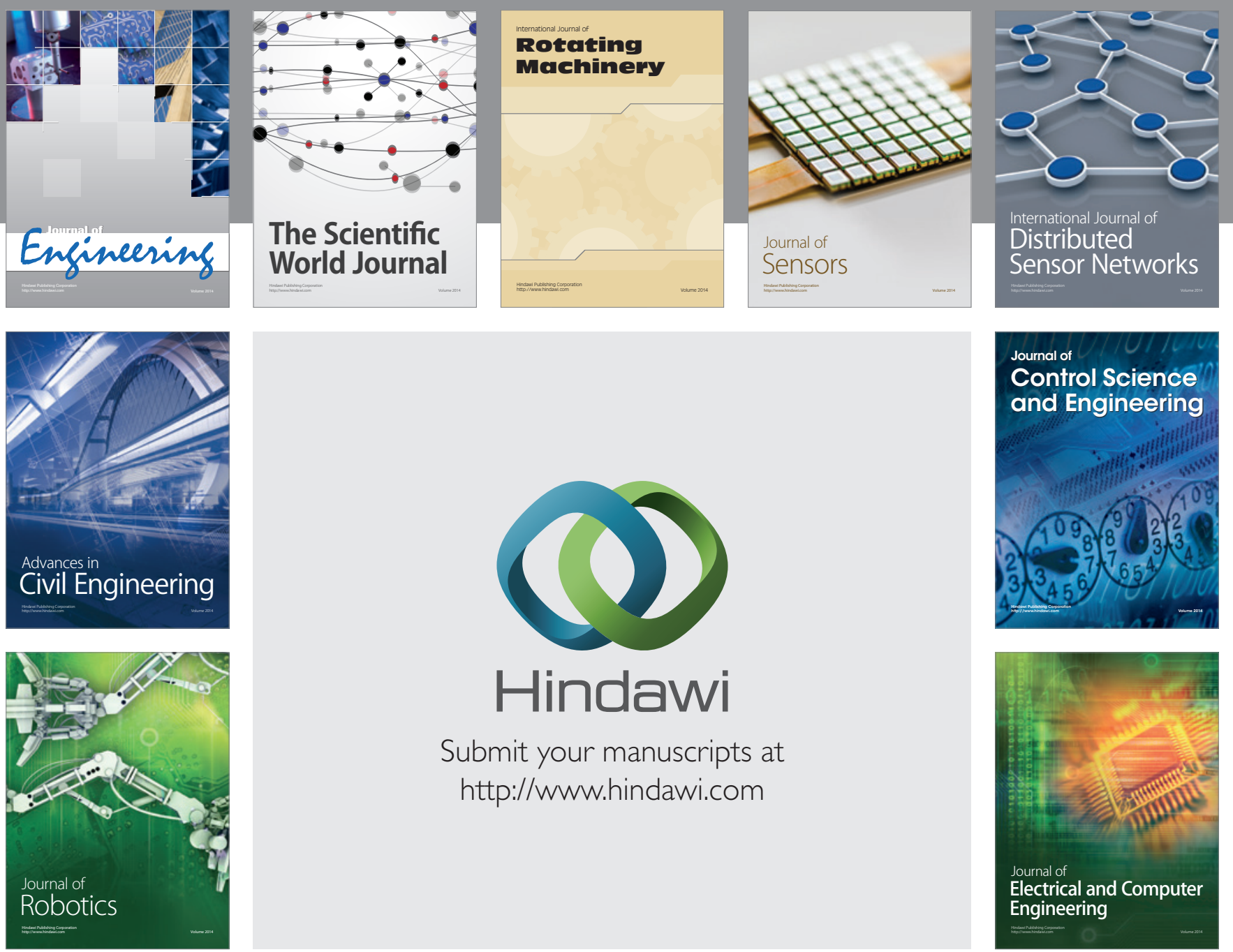

Submit your manuscripts at

http://www.hindawi.com
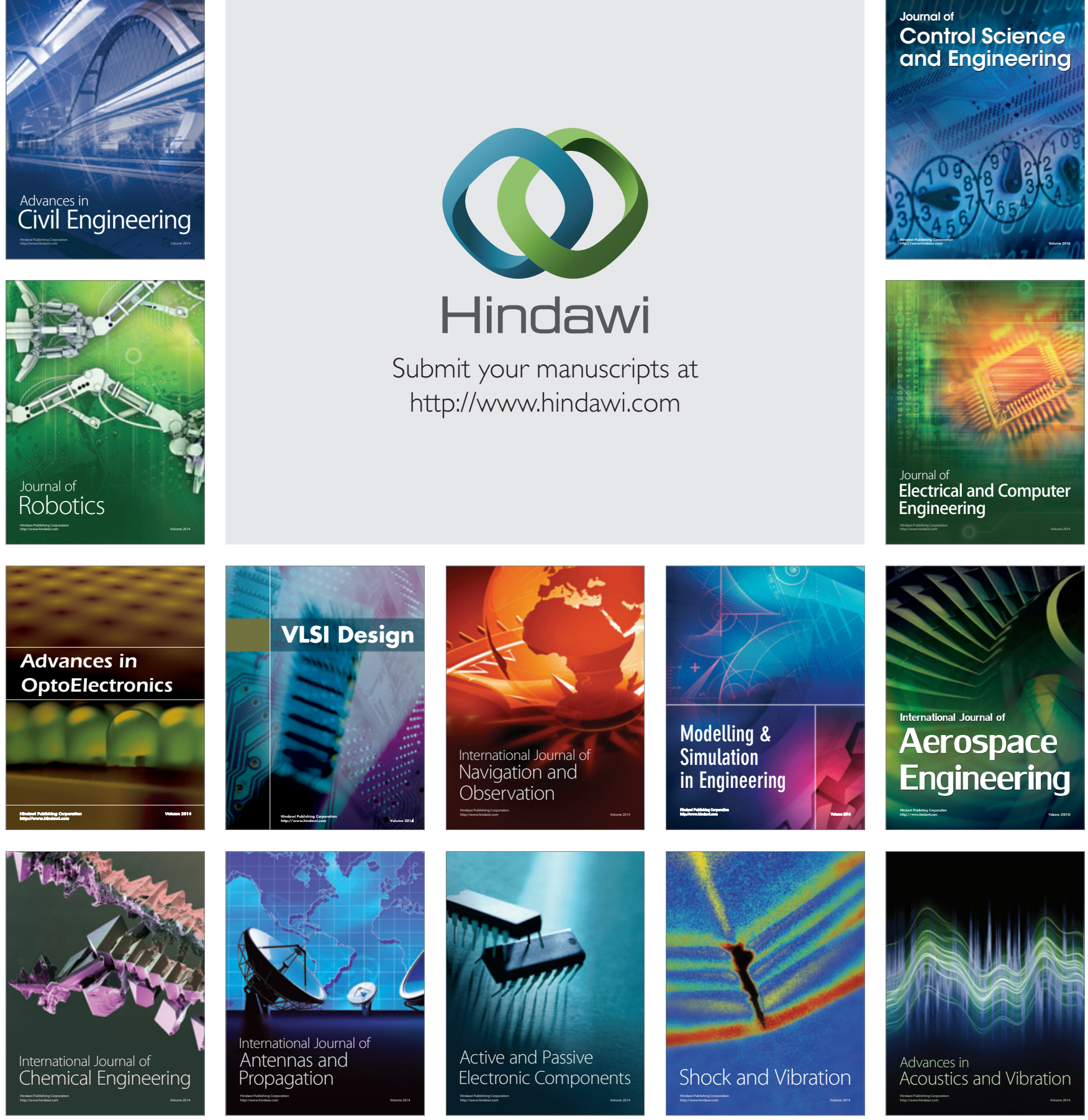